\title{
The Necessity of Developing Rural Education under Chinese Urban and Rural Unitary Strategy
}

\author{
Xin Shang \& Rui Cui \\ College of economics and management, Changchun University of Science and Technology \\ Changchun 130022, China
}

\begin{abstract}
One of the obstacles for unitary development of urban and rural areas is the sluggish growth of farmers' income. Promoting the translation of surplus rural labor is the fundamental measure to resolve the issue of agriculture, countryside and farmers. The significant meaning of developing rural education is that the improvement of the qualities of human capital of farmers can promote the improvement of agricultural production efficiency, quicken the non-agriculture transfer of farmers and promote coordinated development of urban and rural areas.
\end{abstract}

Keywords: Rural education, Balance of urban and rural areas, Transfer of rural labor

Currently, the agenda of Chinese government fully reflects the people foremost idea and the emphasis of number one central file is intensifying the efforts of balancing urban and rural development and strengthening the basic of agriculture development. Now the countryside also faces many new problems and challenges, which lies in: the continual improvement of agricultural production base, more and more stress for the employment of farmers, vast requirement of countryside investment, the price problem of agricultural production brought by global economy and the increase of extreme weather disasters all bring forward higher requirements for the works about three agriculture-related issues.

\section{The basic way of solving three agriculture-related issues is the way of resolving rural labor}

In the 24 years, from 1978 to 2002, the average increasing rate of Chinese agricultural production is $6.2 \%$, which is a good achievement in the Chinese history and worldwide experiences(Lin, Yifu, 2004). Therefore, the key of three agriculture-related issues is that farmers' income is very low comparing to the urban residents while the lower income of farmers also includes the extra education fee for children, the investment cost of production materials and so on. Therefore, the mainly problem for the Chinese three agriculture-related issues is the sluggish growth of farmers' income, whose real income is far lower than urban residents. While the measures for resolving the growth of farmers' income include enhancing the acquisition price of agricultural production, increasing the allowances to farmers from the government, increasing the technical investment for agriculture, adjusting the agricultural productive structure and so on. But, in the view of the social condition about so many Chinese agricultural people, the WTO rules, agricultural characteristics, the traditional policy ideas above cannot improve the rural income long-term and sustainably (Lin, Yifu, 2004). The fundamental and sustainable methods to increase the rural income are to reduce agricultural population and resolve the problem of force of agricultural surplus labor.

2. Rural education is helpful for broadening the extent of force of agricultural labor employed and strengthening the depth of employment

The connection of education and economy is the reproduction of labor force. Education is a means of the reproduction of labor force, however, when economy affords the material base for education, it also require the education to cultivate the talents who can adapt and lead the development of the economy. Schultz,T.W held the opinion that "most capacities of human beings are not being borne with and acquired when the children enter schools at the beginning. The postnatal acquired capacities are unusual. These capacities are strong enough to change the standards of evaluating savings and the formative process of current capitals, which also can change the structure of wages and salaries and the ratio of labor income and capital gain."(Schultz,T.W., 1990)

Currently, the basic, forerunning and global roles of rural education in the Chinese economic construction become increasingly prominent, in the meantime, the concept of rural education is enriched with development of economy. At the first international conference of rural education held in Taian, Shandong in 1998, scholars attending the meeting broke through the geographical limitation of rural education from the point of "the education serving the development of countryside", and firstly defined "rural education" as "the integral educational system serving the development of countryside which consists of anti-illiteracy education, fundamental education, vocational and technical education, continued education of the adults". From it we see that rural education is a dynamic concept, and it should adapt to the changes of economic development and take the responsibility of prompting overall economic development beyond rural area. Through perfecting basic 
education including elementary and middle school, vocational education which adopts to the development of non-agricultural sectors and rural education system including agricultural technology education which provides service for agricultural development, it adopts to the requirements of economic development to laborer quality, explores the contents and modes of rural education in the right place at the right time, adjust them according to the importance of state and rural development constantly and help rural labor force to grab market chances, acquire new skills fast and enhances employment opportunities of non-agricultural industry.

\subsection{Rural education is helpful for strengthening the extent and depth of agricultural labor employment}

From 1978, the household contract responsibility system has been applied in china. Farmers have some right of dominating the factors of production, which mobilizes the productive enthusiasm of farmers and improves the gain production and agricultural productivity. Meanwhile, country reformed the original industrial development strategy and economic system gradually, relaxed regulatory about the factors of agricultural industry and agricultural production, opened the agricultural careers in commerce and industry gradually, performed the reforms breaking through the isolation of countryside and city in the aspects of household register, employment of urban enterprises, food tickets and so on, participated in the international division of labor actively and broadened the development space of labor intensive industry, which enlarged the employment space of agricultural labors and added two ways including that making use of the development of township enterprises to drive the non-agricultural employment of countryside and transferring the agricultural labors to towns from the single farming for the employment channels of countryside. The economic progress and the present research result have shown that education has some positive role in the aspects of not only broadening the employment space of agricultural labor but also deepening the depth of employment.

1) Rural education is the main method to promote the non-agriculture of surplus rural labor.

Now, the principle contradiction of three agriculture-related issues is the solution of employment for surplus rural labor. However, one important factor restricting the transformation of surplus rural labor is the qualities of human capital of these people can not adapt the development of current economy. The increase of the human capital of farmers has a positive impact on the transfer of non-agricultural employment. Much research and economic practices showed the more the level of human capital is, the more the individuals recognize and seize the chances of market and non-agricultural departments are more inclined to hire peasants adapting the ways of degrees or certificate. Educational backgrounds have positive-direction influence on that agricultural laborer improve the employment probability. The studies showed(Chen, Yuyu, 2004), corresponding education increased one year, the chances that people were employed by industry departments increased by $2.2 \%$ (in 1990) and $3.2 \%$ (in 1992) respectively so as to increase average household income by $1.2 \%$ and 1.5 respectively. Especially for poor areas, such employment of agricultural surplus labor in non-agriculture not only is helpful to increase their income but avoid all kinds of unfavorable impact from the fluctuation of agricultural income and the occurrence of the phenomenon that the people who have got rid of poverty become poor again.(Du, Yang, 1999). Johnson G. D. also stressed the importance of rural education (Johnson G. D. 2005). He thought an important problem Chinese agriculture faced was the transfer of rural surplus laborers. The level of Chinese education expense is very low which leads to the low level of the education of rural population so that is cannot adapt to the life style in towns primly. If most of rural population who migrates into towns enjoy the same education in quality and quantities as towners the town will benefit a lot from it. The main reform which helps agricultural labor to make adjustment of non-agricultural employment is to make rural residents and towners get equal chances for education. Currently, our country's rural population quality has become a main problem which restricts rural and overall economic development. Meanwhile there are still a large number of agricultural surplus labors in China and China still faces with huge employment stress. Whether this part of surplus labor resource brings their productivity effect into play rests with the invest of rural human capital by carrier of rural education to a great degree.

(2) The improvement of human capital of farmers is helpful for the improvement of the qualities of agricultural workers and agricultural production efficiency

Schultz,T.W. (Schultz,T.W., 2000) thinks human capital in the forms of education, on-job training and improving health conditions is the main source of agricultural growth. Especially while agricultural growth depends on some kind of production factor which takes technology as the connotation to a large extent, human capital becomes important particularly. What achievements a nation can obtain after applying modern skills and knowledge to agricultural production depends on whether it spends on farmers' education to a great degree. The success of agricultural mechanization in former Soviet Union depends on the former Soviet Union government improve farmers' skills in the forms of training classes and vocational schools to a great degree. Japan began to 
reform traditional agricultural production technologies in order to improve land productivity after 1980s. The agricultural teaching contents in Japan schools are based on native fact, lean agricultural theories including agricultural management from nations such as Germany with similar resource and introduce related plant nutrition science and soil fertilizer Science et.al., which lays the scientific foundation for the development of land-saving technology in Japan afterwards.(Yujiro Hayami. 2002) While Japan schools hire foreign teachers they also select some experienced peasants who are proficient in farming and enthusiastic at studying agronomy as teachers and make them carry on field agricultural teaching. The Agricultural Experimental Farms in various regions play a selective role in the experienced peasants' skills, thus the technique expansion of the experienced peasants becomes effective and feasible indeed. (Yujiro Hayami. 2002)

From the practice in China, the investment in rural human capital also prompted agricultural development. Adopting the model of securities selection to analyze the data from 500 peasants in five counties in Hunan Province, Lin Yifu (Lin, Yifu, 2009) drew the conclusions as follows: compared to traditional technologies, new agricultural technology usually has more expected outcome and larger risk, but education can enhance a decision maker's ability to obtain identification and understand information so as to reduce the risk new technology may bring. Education degree is a main factor to decide whether a peasant adopts hybrid rice and the level he adopts. Schurz noted that, only relying on rich natural resource and farmers' simple characters cannot realize the reformation of traditional agriculture. Only farmers master scientific knowledge about soil, plant, animal and machine, as well as adopt incentive mechanism to stimulate their initiatives in production in order to prompt the improvement of the agricultural efficiency. (Schultz,T.W., 2000)

\section{The economic structural effects brought by the transfer of agricultural labors}

Since 1978 China's countries have produced the household contract responsibility system. Meanwhile the nation has reformed original industrialization development strategy and economic system gradually, relaxed its control of agricultural production factors and products, opened rural industrial-commercial fields, carried out system reform which broke the urban and rural isolation in the aspects of household registration, urban enterprises' employment and food coupon, actively participated in international division of labor and expanded the development space of national labor-intensive industry. Rural channels of employment have increased from single farming to two channels which included the development of township enterprises solved a number of labors in the countryside non-agricultural employment. From the research of the sample data of Chinese peasant household shows (Zhou, Qiren, 1997), in 1994 the agricultural labors resource invests from pure agriculture to concurrent business and non-agricultural industries, and the outcome increases subsequently and their ratio is $1: 2.28: 2.85$. Meanwhile in the process of non-agricultural employment of rural labors, there will be huge structural benefits. Between 1978 and 1994, 1.3 billion labors transferred from agricultural departments to the secondary and tertiary industries and the total net increase of GDP is 777.66billion yuan, which accounts for 33.5\% of our country's total GDP during this period. At the same time, the first industry departments also improve their labor productivity through the non-agricultural transfer of labors. In 1994 the labor productivity increased by $17.91 \%$ and the output per person increased by $104.7 \%$ and more than doubled, which showed the transfer of agricultural surplus labors make Chinese economy release powerful structural productivity. Therefore, from the practice of China, only strengthen rural education the structural effects brought by the transfer of labors can be brought into play further.

\section{The development obstacles of rural education}

The analysis above showed rural education can strengthen the depth and extension of agricultural labors' employment and through corresponding structure effects prompt economic development. But there are still a lot of obstacles to develop rural education for many developing countries including China.

The development obstacles of rural education include the problems of the awareness of governmental departments, farmers' ability to shoulder economically and the setup of contents and systems of rural education et.al. Firstly, from the aspect of the awareness it includes as follows (Schultz,T.W. 2000): traditional concepts think anyone can engaged in agricultural production as long as he is healthy, so it is unnecessary to provide agricultural skills trainings for farmers; The fundamental path to realize economic growth in developing countries is summarized as realization through industrial invest and economic growth is regard as industrial development identically, thus agricultural invest is ignored; Even though the process of economic development needs agricultural modernization, the implementation of measures only attach importance to the invest into agricultural machines, irrigation facilities and agricultural materials while ignoring the impartation of necessary skills and knowledge about efficiently using modern agricultural production factors. Secondly, from the aspect of farmers' ability to shoulder economically, although the basic property of education is public goods and its invest 
should have governmental departments to bear, farmers also need to invest certain economic resource when they accept non-agricultural skills training and agricultural techniques. Besides, for the farmers who have preliminary ability of labors, the opportunity cost of study is higher. Third, to ensure that rural education makes contributions to economic development also depends on the contents of rural education. In order to use modern agricultural production factors effectively, farmers should obtain more practical skills and knowledge of agricultural science and pay more attention to basic education, not just current technological achievement, so that they have abilities to accept new techniques.

\section{Conclusion}

Rural education has a fundamental and forerunning strategic position in the course of the relation between city and countryside. Rural education in the view of urban and rural development is a new education development concept and a comprehensive education view which integrates various regional politics, economics, culture, history et.al so it should make great effects to ensure its implementation from the aspects including management system, orderly invest and the participation individual diversity and policy safeguard et.al and establish a set of long-term effective mechanism to solve the problem of the coordination of urban and rural educational development fundamentally.

\section{References}

Chen, Yuyu. (2004). Rural Modernization and the Pole of Education in Rural Labor Market. Economic Research Journal.

Du, Yang. (1999). The Research of Education Influencing on the supply of nonagricultural work force in poor areas. Chinese Journal of Population Science.

Johnson G. D. (2009). The issue of agriculture, countryside and farmers in the development of economy. Beijing, Chinese Development Press.

Lin, Yifu. (2004). Developing the rural education is the key to resolving the issue of agriculture, countryside and farmers. Guizhou Today.

Lin, Yifu. (2009). The Innovative Application of Education and Agriculture. Beijing, Truth \& Wisdom Press.

Schultz,T.W. (1990). Investment in human capital. Beijing, The Commercial Press.

Schultz,T.W. (2000). Changing the Traditional Agriculture. Beijing: The Commercial Press.

Yujiro Hayami. (2002). Agricultural Economy. Beijing, China Agriculture Press.

Zhou, Qiren. (1997). Opportunity and Capability-the flow and employment of Chinese countryside labour force. Management World. 